\title{
A Generic MODEl For Disease OUTBREAK NOTIFICATION SYSTEMS
}

\author{
Farag Azzedin, Jaweed Yazdani, Salahadin Adam, Mustafa Ghaleb \\ King Fahd University of Petroleum and Minerals \\ Dhahran 31261, Saudi Arabia
}

\begin{abstract}
ABTRACT
Disease outbreak detection, monitoring and notification systems are increasingly gaining popularity since these systems are designed to assess threats to public health and disease outbreaks are becoming increasingly common world-wide. A variety of systems are in use around the world, with coverage of national, international and global disease outbreaks. These systems use different taxonomies and classifications for the detection and prioritization of potential disease outbreaks. In this paper, we study and analyze the current disease outbreak systems. Subsequently, we extract features and functions of typical and generic disease outbreak systems. We then propose a generic model for disease outbreak notification systems. Our effort is directed towards standardizing the design process for typical disease outbreak systems.
\end{abstract}

\section{KEYWORDS}

Disease Outbreak Notification System, Taxonomy, Modeling, Health Systems. ETL, Databases.

\section{INTRODUCTION}

Disease outbreak detection, monitoring and notification systems are increasingly gaining popularity since these systems are designed to assess threats to public health and disease outbreaks are becoming increasingly common world-wide. A variety of systems are in use around the world, with coverage of national, international and global disease outbreaks. These systems use different taxonomies and classifications for the detection and prioritization of potential disease outbreaks. The prime purpose of these systems is ensuing quick detection of possible outbreaks and epidemics.

According to World Health Organization (WHO) [1], the widespread persistence of outbreaks such as MERS, SARS, H5N1 etc., poses immense risks for human life. An unforeseen disease outbreak could lead to a threat on a global scale. A number of factors contribute to this threat including the ability of the disease to mutate into new subtypes, the possibility of the disease to turn highly infectious for humans and the lack of timely response to develop immunity. As per WHO guidelines and recommendations, in the event of an outbreak, member countries are obliged to notify within 24 hours epidemiological information with regards to occurrence/reoccurrence of listed notifiable diseases, the occurrence of a new strain of a listed disease, a significant change in the epidemiology of a listed disease, or the detection of an emerging disease.

It is apparent that the increasing threat of disease outbreaks significantly increases the need to provide timely and accurate information to WHO and public health professionals across many 
jurisdictional and organizational boundaries. Also, the increasing frequency of biological crises, both accidental and intentional, further illustrates that Disease Outbreak Notification System (DONS) needs to be in place to meet the challenges faced by societies across the world. These systems should detect, monitor, prepare, and respond to a disease outbreak. There a large number of systems in existence that detect and prioritize potential disease outbreaks. Various DONS have been designed with different objectives, features and functions. There is no clear and standardized approach in the design and implementation of such systems.

Our effort in this paper is directed towards standardizing and proposing a model to be used as a reference when designing DONS in future efforts. We focus on various DONS that use different taxonomies and classifications for the detection and prioritization of potential disease outbreaks. We study and analyze the current systems. Subsequently, we extract features and functions of typical and generic systems under the DONS umbrella. We then propose a generic model for DONS.

\section{OVERVIEW OF DiSEASE OUTBREAK NOTIFICATION SySTEMS}

The evolution of DONS show a taxonomy that covers various geographies, functions and features based on system and user requirements. BioSense is an Internet-based software system that supports early detection of disease outbreaks by providing techniques for near real-time reporting, related analytics, implementation and automated outbreak detection on a national level. BioSense system collects and evaluates data from ambulatory, clinical laboratory test orders and results from Laboratory Corporation of America laboratory. It presents, summarizes, and visualizes data and analytical results through graphs, maps and tables based on day, source, state, disease type, and metropolitan area. The latest version of this application is BioSense 2.0 which provides data in a distributed cloud computing environment. [2]

The Computer Assisted Search for Epidemics (CASE) is a framework for computer supported outbreak detection. The system developed and currently in use at the Swedish Institute for Communicable Disease Control (SMI) obtains data from SmiNet and performs daily surveillance. It is open source software that removes the personal identification and includes only the specific variables in the CASE database. The system performs outbreak detection in two steps: step 1 identifies different statistical algorithms that detect unexpected or unusual number of cases from collection of patient reports for a particular disease and step 2 initiates an investigation by an epidemiologist (a human expert). If CASE detects an outbreak, step 2 aids in determining whether the detected outbreak indicates an actual outbreak. In some cases, it might be able to detect outbreak diseases earlier than epidemiologists. Moreover, it might detect certain outbreaks that human experts would have overlooked. [3]

Another system, the National Notifiable Diseases Surveillance System (NNDSS) was launched in 1990 and managed by the Australian Government under the support of the Communicable Diseases Network Australia (CDNA). NNDSS collects, analyses, and disseminates data on communicable diseases. NNDSS is involved in national and international health practice and processes public health data through CDNA and other main stakeholders directly into the health system. It has been utilized to notify public health action, especially for the diseases that can be prevented through vaccination. Surveillance epidemiologists analyse the collected data from various jurisdictions every fortnight. In terms of reporting, various reports are placed on the CDA website to be available for public access. Data analysis and reports are also disseminated upon requests from the public, community groups or research organizations. [4] 
HealthMap is another major system that facilitates the monitoring of global infectious diseases. As described by Freifeld et al. [5], this system uses a wide variety of online formal and informal information sources and channels such as Google News, ProMED, GeoSentinel etc. to collect and aggregate content in several languages which is then classified by infectious disease agents, geography and time. The system is based on open-source products, both for its development (Linux, Apache) and its continued use (Google Maps, Google Translate API, etc). The classification mechanism is entirely automated, and is based on algorithms that use factors such as the frequency and time frame of alerts as well as the number of sources reporting the information to identify potential health events. An option is also provided for users to report outbreaks of infectious diseases in their region.

Another novel approach for the detection of disease outbreaks and their forecasting is the INFERNO system, short for Integrated Forecasts and Early Enteric Outbreak. Nauvoma et al. [6] describe this system in their paper, explaining the use of a concept known as an "outbreak signature" that allows for the forecasting of outbreaks using existing knowledge of infectious disease epidemiology. The existence of the signature is based on the highly habitual nature of infectious disease events, and can be used to generate a long-term forecast. They further elaborate upon the four components of the system - training, warning and flagging, signature forecasting, and evaluation - each of which contribute to the observational knowledge about the nature and incidence of infection. The INFERNO system effectiveness in predicting an outbreak has been highlighted in the paper via the incidence of a substantial waterborne gastroenteritis disease outbreak in Milwaukee, Wisconsin in 1993. The system is slated to improve as information about infectious disease incidence and exposure increases, with improved predictions of outbreaks and greater accuracy.

Zelicoff et al.[7], in their paper, present the Rapid Syndrome Validation Project (RSVP), a system that allows for early detection of outbreaks and emerging biological threats. It is a collaboration project of several institutions: the Sandia and Los Alomos National Laboratories, the University Of New Mexico Department Of Emergency Medicine, and the NM Department of Health Office of Epidemiology. The system is built using Java and is platform-independent, and can be run with both a standalone Java database and a relational database such as Oracle for flexibility in deployment.

The RSVP system relies primarily on reports by medical personnel and provides an interface through which physicians quickly and easily enter clinical and demographic information about patients showing unusual or atypical symptoms and syndromes. This information is then used to assess potential emerging epidemics or outbreaks and send out early warning alerts to local departments of health for necessary investigation. The system also allows physicians to stay informed of new health alerts, as well as provides them feedback of any similarities between their reports and previous reported cases. The system facilitates the exchange of information between medical personnel and increases their involvement in disease and outbreak control.

In total, as part of our team effort, we identified and analysed 21 systems that were placed under our classification of DONS category. To match space requirements, only the study of a few systems has been presented in this section. However, in the next section we have included the taxonomy and analysis of all 21 systems.

\section{Generic Architecture \& Design Of Disease Outbreak Systems}


In this subsection, we present the detailed architecture, function and technical features of the DONS system. Disease outbreak notification systems, in a generic format, collect, detect or relay disease outbreaks by majorly following the activity workflow illustrated in Figure 1 Figure 1 [30]. A physician initiates by sending a laboratory specimen to a microbiologist or an epidemiologist in the local or provincial laboratory. The laboratory then sends back the results to the physician. If the results are positive to one of the listed diseases, then the physician or the provincial laboratory notifies the local, regional or provincial health unit.

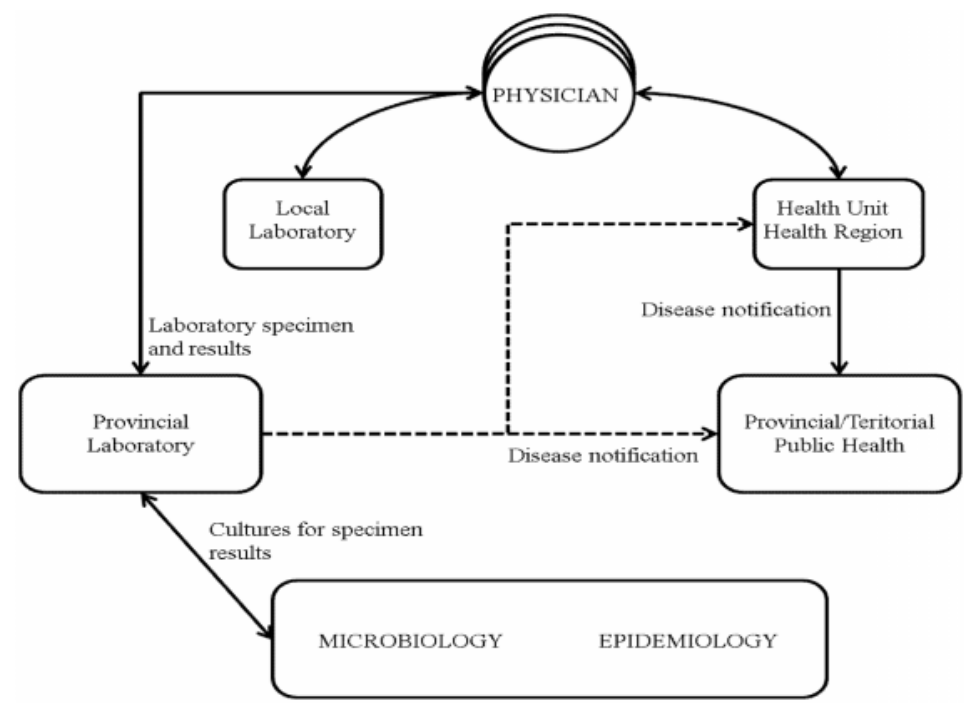

Figure 1: Disease Outbreak Activity Workflow

The notifications generated by the disease outbreak systems are further processed for distribution, through an escalation mechanism to varying categories of recipients as illustrated in Figure 2

Figure 2. When any health related event is detected, then primary control measures are taken at the local community level or at the district level. The event is also reported to the provincial public health center where the event is investigated and additional control measures are taken. The provincial public health center then reports its findings to the national public health center which conducts formal assessment and takes containment and control measures. The national public health center may then report to an international public health center which takes other control measures and makes further recommendations. 


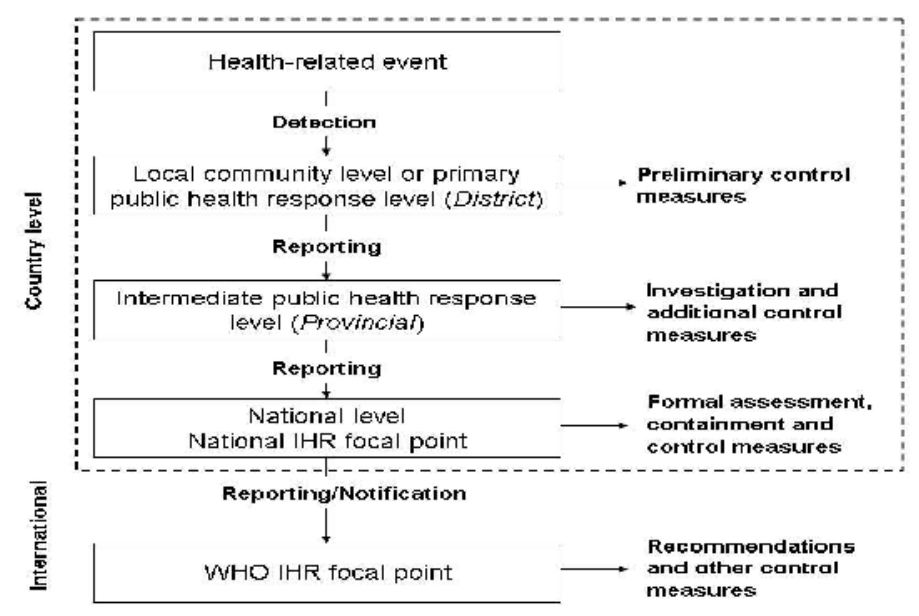

Figure 2: Disease Outbreak Escalation Mechanism

\section{ANALysis \& TAXonomy Of DONS}

In developing the taxonomy covering the numerous implementations of DONS across the world, we identified major criteria for categorizing these systems. This section describes a taxonomy based on how, when, and where metrics of the 21 DONS we have analyzed. The "how" metric presents system features such as detection techniques, transparency, various layers of granularity, and disease coverage. The "when" metric looks at issues such as whether the systems, based on time frames, are static or dynamic, and whether the detection analysis is relayed in real time. The "where" metric is concerned with the geographical coverage and whether the system's detections and analysis are complete. As a consequence of the disease outbreak workflow analysis, we observed that most systems address the targeted recipients through a process of applying several metrics. Figure 3 below illustrates six metrics applied to notifications in most of the disease outbreak notifications systems.

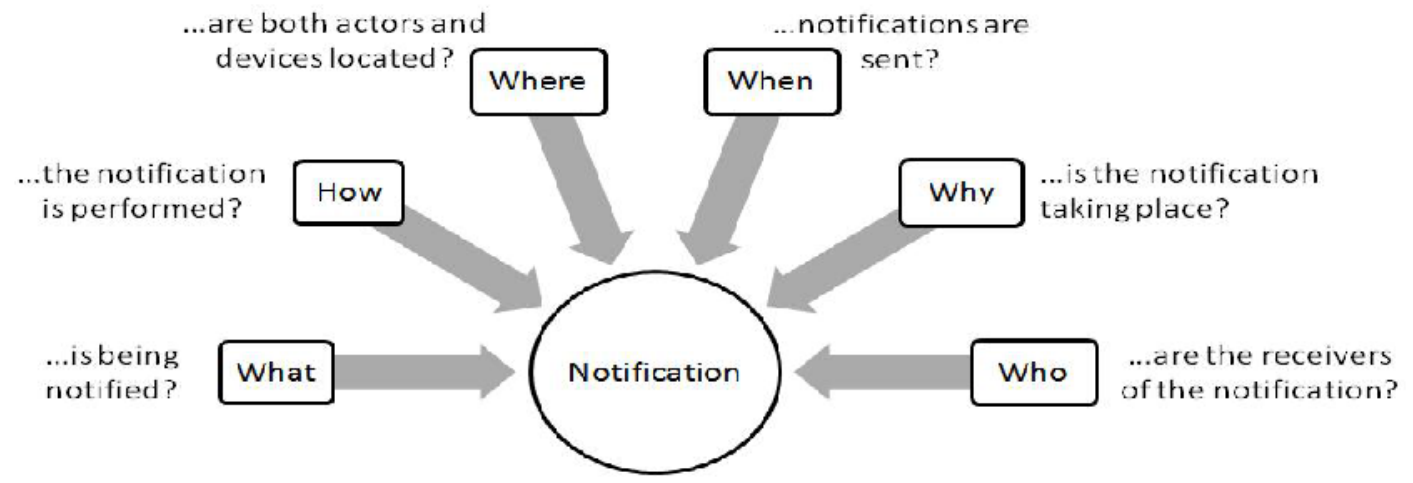

Figure 3: Disease Outbreak Notification Metrics

After a detailed study of many DONS, we identified a number of important features. We then classified the features into dimensions and then dimensions into categories. We classified all the features into 4 categories, namely the Collection \& Analysis category, the Core Functions category, the System features category, and Support Functions category. 
The features in the first category, which is the "Collection \& Analysis" category, are about who owns the data, where each datum comes from, how the data is collected, what the data format is, and how the data is analyzed. Table 2Error! Reference source not found. shows the dimension and the description of each feature in this category.

The features in the second category, the "Core Functions" category, are about how a disease outbreak is detected, confirmed, registered, and interpreted. They are also about how the detection is reported, formatted, communicated, and who the target entities are. Table 3Error! Reference source not found. shows the dimension and the description of each feature in this category.

The third category, which is the "System Features" category, consists of features which are about completeness, timeliness, usefulness, mobility, reliability, flexibility, and others. These features are described in Table 4Error! Reference source not found..

The last category, which is the "Support Functions \& System Interfaces", includes features related to implementation, monitoring, reporting, and evaluation standards, training, communication, evaluation, and administration. It also includes features related to how the system interacts with external actors.

\subsection{Categorization of Current DONS}

The study and analysis of DONS and related systems must provide a mechanism to categorize the functionalities, features and capabilities of these systems. The major criteria for inclusion of the systems in our study were based on four categories that were developed to classify the systems. The four categories are: Collection \& Analysis, Core Functions, System Features, and Support Functions. The Collection \& Analysis category classifies the systems based on who owns the disease data, where such data comes from, what is the data format, and how the data is collected and analyzed. Table 1 shows the dimension and the description of each feature in this category.

Table 1 : Features of the "Collection \& Analysis" category

\begin{tabular}{|c|c|c|c|}
\hline Category & Dimension & Feature & Description \\
\hline \multirow{6}{*}{ 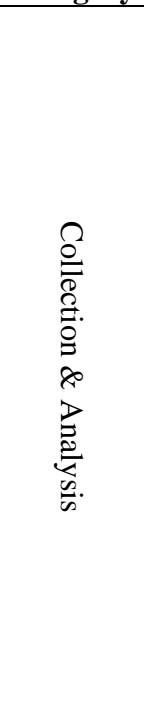 } & \multirow{4}{*}{ Collection } & Stakeholders & $\begin{array}{l}\text { System owners \& users including health-care } \\
\text { providers, other DONS systems, experts, institutions, } \\
\text { local \& regional health authorities }\end{array}$ \\
\hline & & Data Sources & $\begin{array}{l}\text { Health institutions such as hospitals, clinics, } \\
\text { laboratories and pharmacy }\end{array}$ \\
\hline & & $\begin{array}{l}\text { Collection } \\
\text { Strategy }\end{array}$ & $\begin{array}{l}\text { Surveillance disease } \\
\text { collection list, collection objectives, } \\
\text { transformation strategy }\end{array}$ \\
\hline & & Data Formats & $\begin{array}{l}\text { Standard data formats (e.g., XML, Standard Storage } \\
\text { Format [SSF] for GPS files; Tagged Image File } \\
\text { Format [TIFF] or Joint Photographic Experts Group } \\
\text { [JPEG] for photographs; and Excel or InfoPath } \\
\text { formats for electronic forms). }\end{array}$ \\
\hline & \multirow{2}{*}{ Analysis } & $\begin{array}{l}\text { Computation } \\
\text { Detection } \\
\text { Algorithms } \\
\end{array}$ & $\begin{array}{l}\text { Detection algorithms capable of analyzing } \\
\text { epidemiological and laboratory data }\end{array}$ \\
\hline & & $\begin{array}{l}\text { Statistical } \\
\text { Analysis }\end{array}$ & $\begin{array}{l}\text { Statistical analysis (e.g. } \text { Threshold, SaTScan } \\
\text { Poisson, SaTScan Space-Time permutation, and } \\
\text { Farrington) }\end{array}$ \\
\hline
\end{tabular}

Table 2 : Features of the "Core Functions" category

\begin{tabular}{|l|l|l|l|}
\hline Category & Dimension & Feature & Description \\
\hline
\end{tabular}




\begin{tabular}{|c|c|c|c|}
\hline \multirow{8}{*}{ 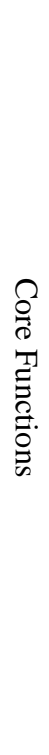 } & \multirow{2}{*}{ Case-Level } & Detection & $\begin{array}{l}\text { Defined process to identify individual cases as } \\
\text { isolated cases or contributing to outbreaks }\end{array}$ \\
\hline & & $\begin{array}{l}\text { Confirm \& } \\
\text { Register }\end{array}$ & $\begin{array}{l}\text { Capacity to register/confirm as outbreak cases } \\
\text { based on epidemiological and laboratory data }\end{array}$ \\
\hline & \multirow{3}{*}{ Group-Level } & $\begin{array}{l}\text { Signal } \\
\text { Extraction }\end{array}$ & $\begin{array}{l}\text { Generate statistically significant signals based on } \\
\text { grouped data for identifying outbreaks }\end{array}$ \\
\hline & & Interpretation & $\begin{array}{l}\text { Interpret signals as outbreaks and map to } \\
\text { appropriate alert and epidemic thresholds for } \\
\text { public health action }\end{array}$ \\
\hline & & Reporting & $\begin{array}{l}\text { Report confirmed outbreaks in a timely manner } \\
\text { based on urgency }\end{array}$ \\
\hline & \multirow{3}{*}{ Notifications } & $\begin{array}{l}\text { Communication } \\
\text { Procedures }\end{array}$ & $\begin{array}{l}\text { Appropriate and standard communication methods } \\
\& \text { medium to ensure delivery to identified } \\
\text { stakeholders }\end{array}$ \\
\hline & & Target Entities & $\begin{array}{l}\text { Appropriate entities such as health-care providers, } \\
\text { other DONS systems, experts, institutions, local \& } \\
\text { regional health authorities }\end{array}$ \\
\hline & & $\begin{array}{l}\text { Output/ } \\
\text { Message } \\
\text { Formats }\end{array}$ & $\begin{array}{l}\text { XML, Standard Storage Format }[\mathrm{SSF}] \text { for GPS } \\
\text { files; TIFF or JPEG for photographs; and Excel or } \\
\text { InfoPath formats for electronic forms; \& pdf }\end{array}$ \\
\hline
\end{tabular}

The Core Functions category identifies how a disease outbreak is detected, confirmed, registered, and interpreted. In addition, this category also outlines how the detection is reported, formatted, communicated, and who the target entities are.

Table 2 shows the dimension and the description of each feature in this category. The System Features category consists of features such as completeness, timeliness, usefulness, mobility, reliability, flexibility, and others. These features are described in Table 3.

The last category Support Functions \& System Interfaces includes features related to implementation, monitoring, reporting, evaluation standards, training, communication, evaluation, and administration. It also includes features related to how the system interacts with external actors. These features are described in Table 4.

Table 3 : Features of the "System Features" category

\begin{tabular}{|c|c|c|c|}
\hline Category & Dimension & Feature & Description \\
\hline \multirow{7}{*}{ 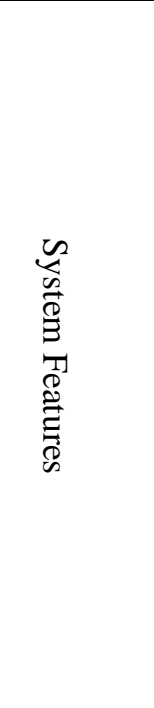 } & \multirow{7}{*}{ Attributes } & Completeness & $\begin{array}{l}\text { Completeness of case reporting, reporting sites } \\
\text { and notification form }\end{array}$ \\
\hline & & Timeliness & $\begin{array}{l}\text { Data submitted in a timely manner e.g. } \\
\text { (immediately, weekly and monthly reporting) to } \\
\text { investigate and implement control measures. }\end{array}$ \\
\hline & & Usefulness & $\begin{array}{l}\text { The value of data to use in detecting and } \\
\text { responding to outbreak in appropriate time }\end{array}$ \\
\hline & & Real-time & $\begin{array}{l}\text { Monitoring the case sources reporting and other } \\
\text { functions in real time, helping to identify and } \\
\text { investigate outbreaks in real time }\end{array}$ \\
\hline & & Coverage & $\begin{array}{l}\text { The system can be used at various levels e.g. state, } \\
\text { region, country, continent or global level }\end{array}$ \\
\hline & & Portability & $\begin{array}{l}\text { The system can be run in multiple platforms and } \\
\text { uses data standards such as XML }\end{array}$ \\
\hline & & Sensitivity & $\begin{array}{l}\text { Sensitive to detect all possible cases/patterns for } \\
\text { known and unknown diseases and report to the } \\
\text { notification system }\end{array}$ \\
\hline
\end{tabular}




\begin{tabular}{|l|l|l|}
\hline Availability & $\begin{array}{l}\text { Availability of system to be used at anytime, } \\
\text { anywhere depending on its area of coverage }\end{array}$ \\
\hline Accessibility & $\begin{array}{l}\text { Access the system through various platforms such } \\
\text { as web browsers, smart devices etc. and by system } \\
\text { staff to support and maintain the system }\end{array}$ \\
\hline Usability & $\begin{array}{l}\text { The system can be used by predefined users to } \\
\text { effectively and efficiently respond to outbreaks. }\end{array}$ \\
\cline { 2 - 3 } $\begin{array}{l}\text { Interface } \\
\text { Design }\end{array}$ & $\begin{array}{l}\text { System Interface is easy to use, easy to } \\
\text { understand, and allow users to achieve their needs } \\
\text { through intuitive interfaces .e.g. (GUI) }\end{array}$ \\
\hline Mobility & $\begin{array}{l}\text { Native support for mobile devices such as smart } \\
\text { phones, tablets etc. }\end{array}$ \\
\hline Flexibility & $\begin{array}{l}\text { Ability to change and modify to detect new } \\
\text { outbreak cases, modifying and redefining case } \\
\text { definitions and threshold values }\end{array}$ \\
\hline Specificity & $\begin{array}{l}\text { Ability to detect false positive and false negative } \\
\text { cases }\end{array}$ \\
\hline
\end{tabular}

Table 4 : Features of the "Support Functions \& System Interface" category

\begin{tabular}{|c|c|c|c|}
\hline Category & Dimension & Feature & Description \\
\hline \multirow{8}{*}{ 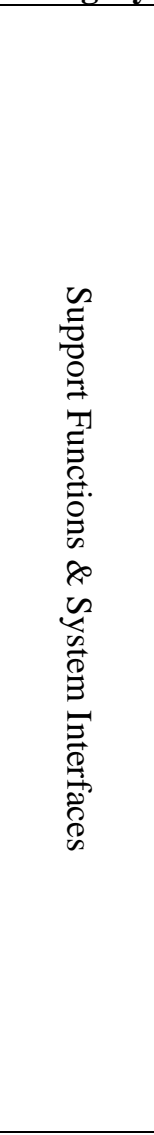 } & \multirow{5}{*}{$\begin{array}{l}\text { Support } \\
\text { Functions }\end{array}$} & Standards & $\begin{array}{l}\text { Use of standards for implementation, } \\
\text { monitoring and evaluation, reporting (e.g. } \\
\text { guidelines for priority diseases, action } \\
\text { thresholds, data management tool, and } \\
\text { guidelines for outbreak detection ...) }\end{array}$ \\
\hline & & Training & $\begin{array}{l}\text { Training users and staff to use the system e.g. ( } \\
\text { laboratory, epidemiology and health care } \\
\text { persons, administrators) }\end{array}$ \\
\hline & & Communication & $\begin{array}{l}\text { Effective and appropriate medium at each level } \\
\text { to support reporting and feedback functions }\end{array}$ \\
\hline & & $\begin{array}{l}\text { Monitoring \& } \\
\text { Evaluation }\end{array}$ & $\begin{array}{l}\text { Monitor and evaluate the system to ensure that } \\
\text { all planned activities for system are on track }\end{array}$ \\
\hline & & $\begin{array}{l}\text { System } \\
\text { Administration }\end{array}$ & $\begin{array}{l}\text { Controlling and maintaining the system and } \\
\text { ensuring that all activities are executed } \\
\text { according to schedule }\end{array}$ \\
\hline & \multirow{3}{*}{$\begin{array}{l}\text { Networking } \\
\& \\
\text { Partnerships }\end{array}$} & $\begin{array}{l}\text { Experts \& \& } \\
\text { Institutions }\end{array}$ & $\begin{array}{l}\text { Support for an expert who is a physician or a } \\
\text { health professional who is expert in an } \\
\text { identified disease; when DONS detects a } \\
\text { potential disease outbreak, it notifies a number } \\
\text { of experts and/or institutions of the disease by } \\
\text { sending messages to their mobile phones }\end{array}$ \\
\hline & & Coordination & $\begin{array}{l}\text { Coordinating between the stakeholders and } \\
\text { implementers for using the system in an } \\
\text { effective way }\end{array}$ \\
\hline & & Feedback & $\begin{array}{l}\text { Collection and processing of stakeholder } \\
\text { response to newsletters, bulletins and } \\
\text { supervisory visits }\end{array}$ \\
\hline
\end{tabular}

\section{Critical Features in DONS}


As stated earlier, the functionalities and features listed in Tables 1 to 4 were identified based on various features and functionalities that exist in the current DONS. In order to be accurate, an initial scan of all the functionalities and features were collected and filtered to come with teh list of critical features required in a DONS.

The objective of this exercise was to include, through a rigorous process, all functionalities and features critical to a DONS system and then analyse the current DONS based on their adherence to the entries in the Tables 1 to 4 . The justification for inclusion of the features as critical was based on several criteria including functional, technical, geographical and system factors.

We analyzed and classified 21 systems through this process. The result of our analysis is presented in Tables 5 and 6 . This analysis was done through a detailed study of all the system by analyzing information from multiple sources. In order to ensure that the data collected during analysis is accurate, we carefully validated each feature mentioned in Tables $5 \& 6$ from more than one source. The primary references are listed in the first column of the two tables. Additional secondary references were also used in validating the contents of Tables $5 \& 6$.

Table 5 : Main features of existing major DONS 
International Journal of Computer Science \& Information Technology (IJCSIT) Vol 6, No 4, August 2014

\begin{tabular}{|c|c|c|c|c|c|c|c|c|c|c|c|c|c|c|c|}
\hline \multirow[b]{3}{*}{ 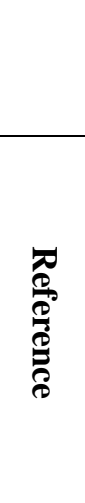 } & \multirow[b]{3}{*}{ System Name } & \multicolumn{6}{|c|}{ Collection \& Analysis } & \multicolumn{8}{|c|}{ Core Functions } \\
\hline & & \multicolumn{4}{|c|}{ Collection } & \multicolumn{2}{|c|}{ Analysis } & \multicolumn{2}{|c|}{$\begin{array}{l}\text { Case- } \\
\text { Level }\end{array}$} & \multicolumn{3}{|c|}{$\begin{array}{c}\text { Group- } \\
\text { Level }\end{array}$} & \multicolumn{3}{|c|}{ Notifications } \\
\hline & & $\mid \begin{array}{l}\frac{n}{2} \\
\overrightarrow{0} \\
\hat{0} \\
\frac{0}{0} \\
0 \\
\frac{0}{2} \\
\infty \\
\infty\end{array}$ & 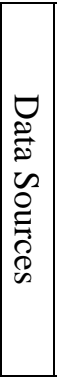 & 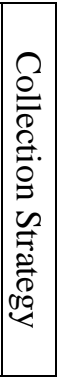 & 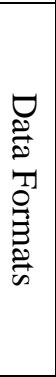 & 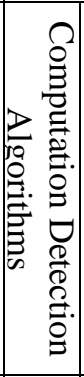 & 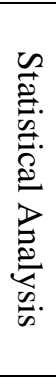 & 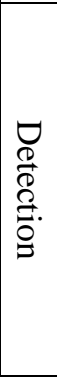 & 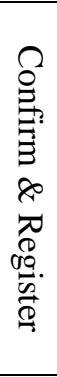 & 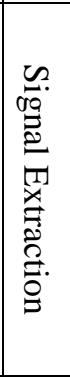 & 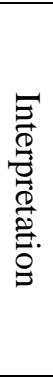 & 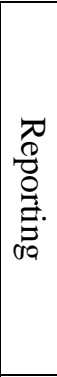 & 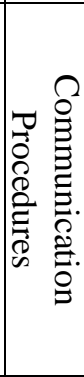 & 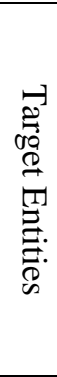 & 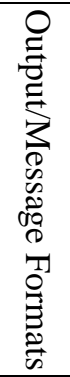 \\
\hline$[8]$ & Aegis & & $\checkmark$ & & $\checkmark$ & & $\checkmark$ & $\checkmark$ & & & $\checkmark$ & $\checkmark$ & & $\checkmark$ & \\
\hline [9] & Argus & & & & & $\checkmark$ & & $\checkmark$ & $\checkmark$ & & & $\checkmark$ & & & \\
\hline [10] & BioAlirt & & $\checkmark$ & & & & $\checkmark$ & $\checkmark$ & & $\checkmark$ & $\checkmark$ & $\checkmark$ & & $\checkmark$ & \\
\hline [11] & BioDefend & & & & & & & $\checkmark$ & & & & $\checkmark$ & & & \\
\hline [12] & BioPortal & & & & & $\checkmark$ & $\checkmark$ & $\checkmark$ & & $\checkmark$ & $\checkmark$ & $\checkmark$ & & $\checkmark$ & $\checkmark$ \\
\hline [2] & BioSense & $\checkmark$ & $\checkmark$ & $\checkmark$ & $\checkmark$ & & $\checkmark$ & $\checkmark$ & $\checkmark$ & $\checkmark$ & $\checkmark$ & $\checkmark$ & & $\checkmark$ & $\checkmark$ \\
\hline [13] & BioStorm & & $\checkmark$ & $\checkmark$ & $\checkmark$ & $\checkmark$ & $\checkmark$ & & & $\checkmark$ & $\checkmark$ & $\checkmark$ & & $\checkmark$ & $\checkmark$ \\
\hline [14] & BTsurveillance & & $\checkmark$ & & & & $\checkmark$ & $\checkmark$ & & & & $\checkmark$ & & $\bar{\checkmark}$ & $\checkmark$ \\
\hline [3] & Case & $\checkmark$ & $\checkmark$ & & $\checkmark$ & & $\checkmark$ & $\checkmark$ & $\checkmark$ & $\checkmark$ & $\checkmark$ & $\checkmark$ & $\checkmark$ & $\checkmark$ & $\checkmark$ \\
\hline [15] & Distribute & $\checkmark$ & $\checkmark$ & $\checkmark$ & $\checkmark$ & & & $\checkmark$ & & & & $\checkmark$ & $\checkmark$ & $\checkmark$ & \\
\hline [16] & EARS & & & & & $\checkmark$ & $\checkmark$ & $\checkmark$ & $\checkmark$ & & & $\checkmark$ & & $\checkmark$ & \\
\hline [17] & Essence II & $\checkmark$ & $\checkmark$ & $\checkmark$ & $\checkmark$ & $\checkmark$ & $\checkmark$ & $\checkmark$ & $\checkmark$ & $\checkmark$ & $\checkmark$ & & $\checkmark$ & $\checkmark$ & $\checkmark$ \\
\hline [18] & EWRS & & & & & & & & & & $\checkmark$ & $\checkmark$ & $\checkmark$ & $\checkmark$ & \\
\hline [5] & HealthMap & & $\checkmark$ & $\checkmark$ & & & & $\checkmark$ & & $\checkmark$ & & $\checkmark$ & & $\checkmark$ & $\checkmark$ \\
\hline [19] & TESSy & $\checkmark$ & $\checkmark$ & $\checkmark$ & $\checkmark$ & $\checkmark$ & & $\checkmark$ & $\checkmark$ & & & & $\checkmark$ & $\checkmark$ & $\checkmark$ \\
\hline [6] & Inferno & & & & & $\checkmark$ & & $\checkmark$ & $\checkmark$ & $\checkmark$ & & $\checkmark$ & & & \\
\hline [20] & NEDSS & $\checkmark$ & & & $\checkmark$ & & & & & & & $\checkmark$ & & & \\
\hline [4] & NNDSS & & & & & & & & & & $\checkmark$ & $\checkmark$ & & $\checkmark$ & \\
\hline [42] & RODS & $\checkmark$ & $\checkmark$ & $\checkmark$ & $\checkmark$ & $\checkmark$ & $\checkmark$ & $\checkmark$ & $\checkmark$ & & & & $\checkmark$ & $\checkmark$ & $\checkmark$ \\
\hline [7] & RSVP & $\checkmark$ & $\checkmark$ & & $\checkmark$ & & & $\checkmark$ & & & & $\checkmark$ & $\checkmark$ & $\checkmark$ & $\checkmark$ \\
\hline [21] & SmiNet & $\checkmark$ & $\checkmark$ & & & & & $\checkmark$ & $\checkmark$ & & & $\checkmark$ & & & $\checkmark$ \\
\hline
\end{tabular}


International Journal of Computer Science \& Information Technology (IJCSIT) Vol 6, No 4, August 2014

Table 6 : More main features of existing DONS

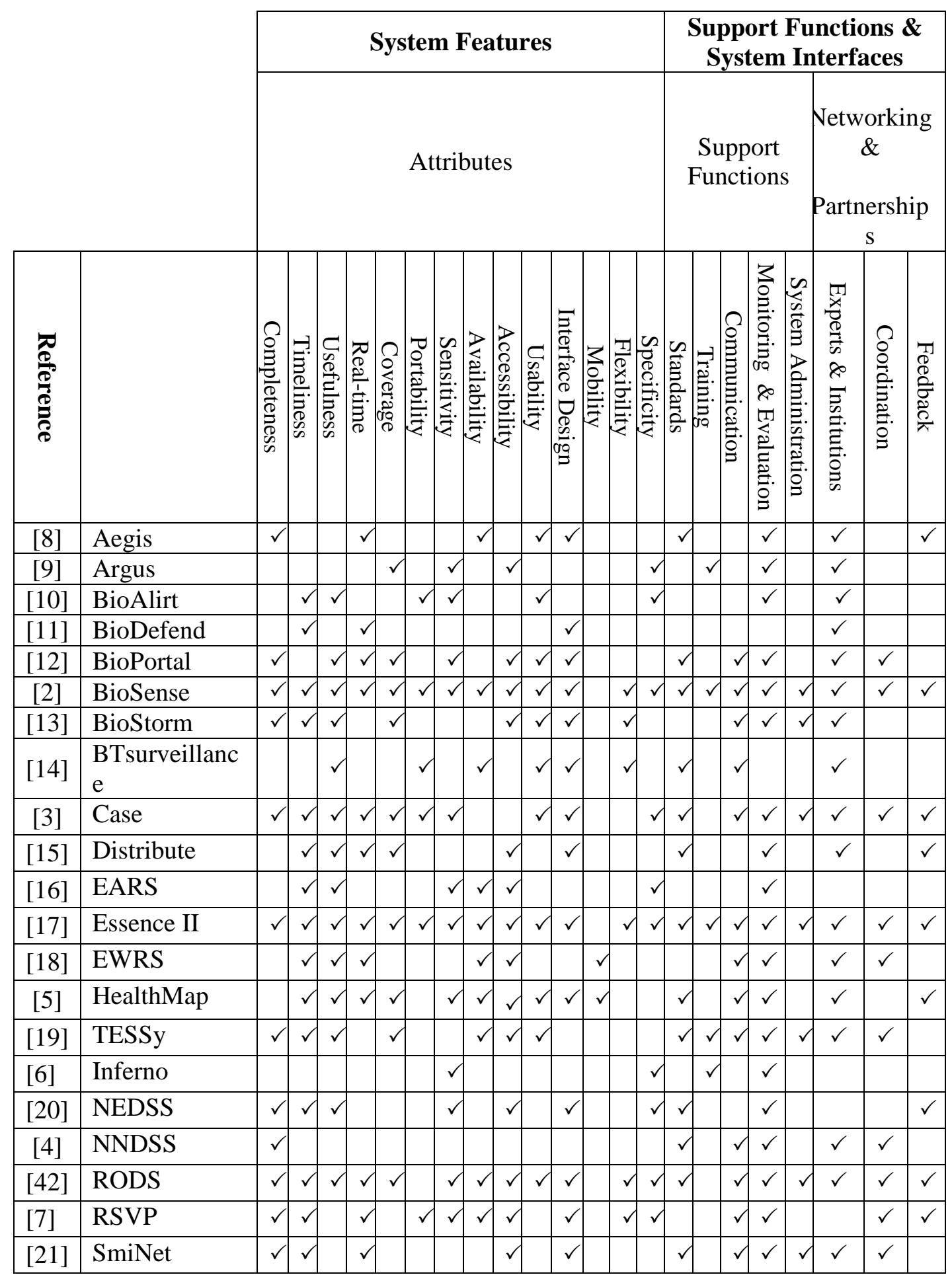

As discussed before, DONS are classified as belonging to various categories including collection, analysis or reporting systems. Some systems are hybrid systems since they combine features, not necessarily all, from each of these categories. A system that has all the features of all the 
categories is referred to as a complete system otherwise it is classified as a partial system. Based on the analysis of the systems in our study, Figure 4 shows examples of partial and complete systems. For example, the Australian NNDSS is a hybrid system where as Swedish SmiNet is only a data collection system.

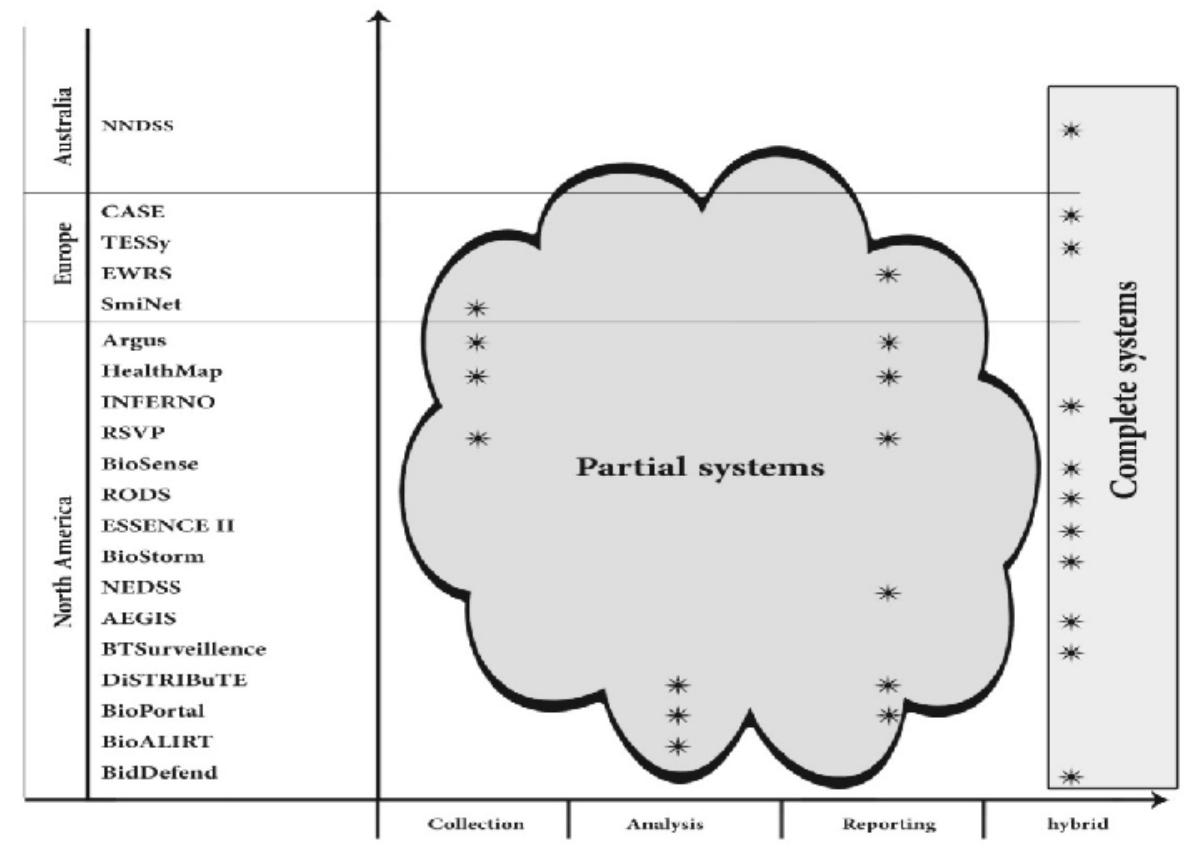

Figure 4: Examples of partial and hybrid systems

\section{Model OF A DONS}

We propose that a DONS must detect potential disease outbreaks and notifies preregistered experts about the outbreak as a mandatory requirement. Based on the taxonomy proposed in the previous section, we have identified the critical features that the DONS should have to satisfy the mandatory requirements, referred to as Core Features in Table 7.

Table 7 : Core features of the DONS

\begin{tabular}{|c|c|c|c|c|c|c|c|c|c|c|c|c|c|c|}
\hline \multirow{3}{*}{ 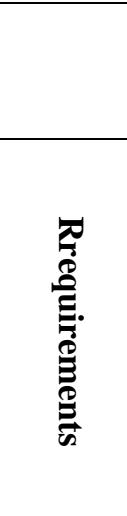 } & \multicolumn{6}{|c|}{ Collection \& Analysis } & \multicolumn{8}{|c|}{ Core Functions } \\
\hline & \multicolumn{4}{|c|}{ Collection } & \multicolumn{2}{|c|}{ Analysis } & \multicolumn{2}{|c|}{$\begin{array}{l}\text { Case- } \\
\text { Level }\end{array}$} & \multicolumn{3}{|c|}{$\begin{array}{l}\text { Group- } \\
\text { Level }\end{array}$} & \multicolumn{3}{|c|}{ Notifications } \\
\hline & 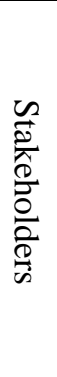 & 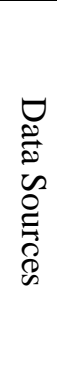 & 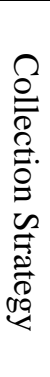 & 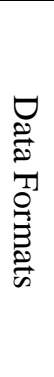 & 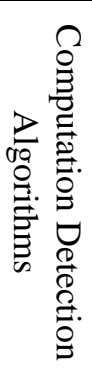 & 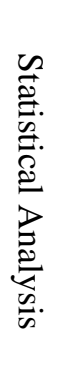 & 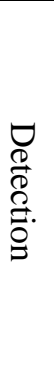 & 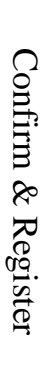 & 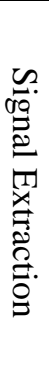 & 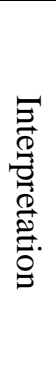 & 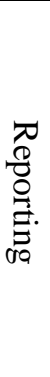 & 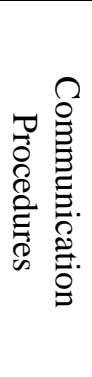 & 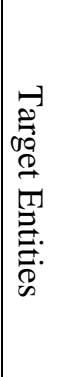 & 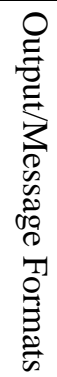 \\
\hline DONS & $\checkmark$ & $\checkmark$ & $\checkmark$ & $\checkmark$ & $\checkmark$ & $\checkmark$ & $\checkmark$ & $\checkmark$ & $\checkmark$ & $\checkmark$ & $\checkmark$ & $\checkmark$ & $\checkmark$ & $\checkmark$ \\
\hline
\end{tabular}


We also propose that a Disease Outbreak Notification System (DONS), support the additional features listed in Table 8 .

Table 8 : Additional features of the existing DONS

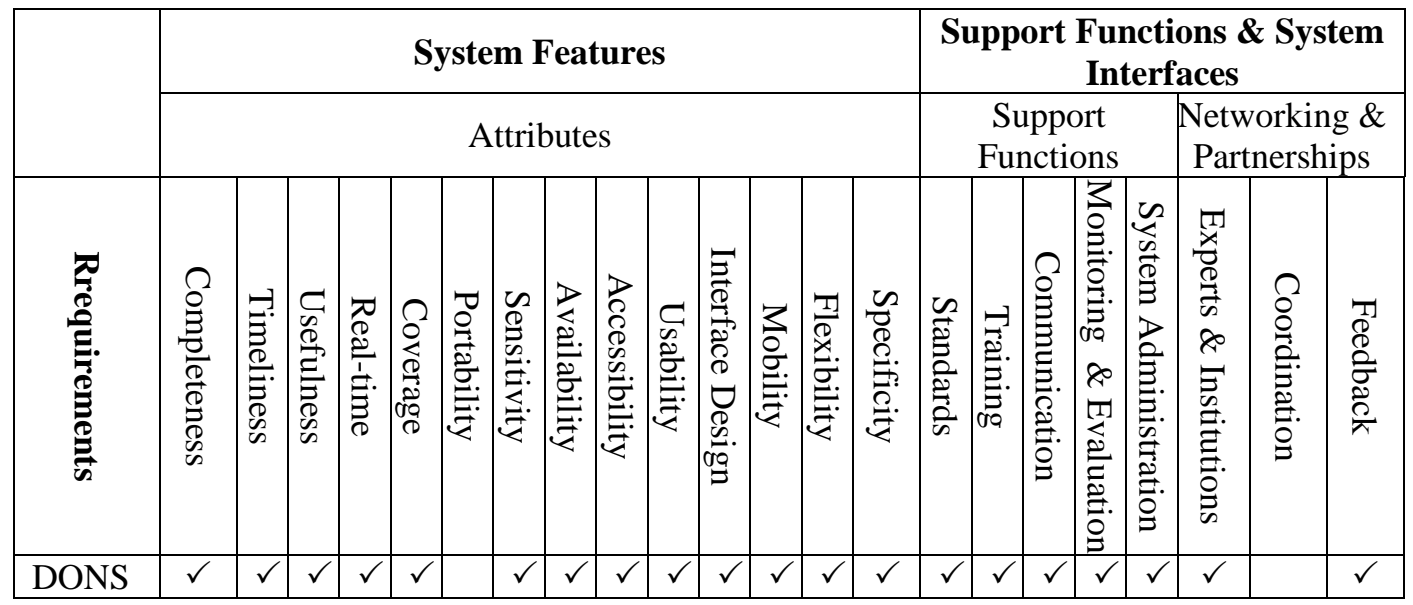

\subsection{High-Level Design of DONS}

DONS interacts with three groups of external actors, namely, case sources, institutions, and experts. Figure 5 shows the context diagram of the DONS.

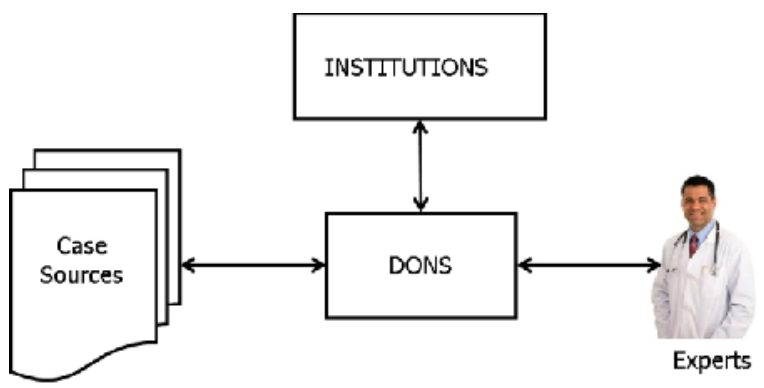

Figure 5: The DONS context diagram

A case source is a health unit such as a hospital, a clinic, or a pharmacy which reports cases of notifiable diseases to DONS. DONS maintains a list of notifiable diseases. A case source reports diseases in the list of notifiable diseases, but it may also report unknown diseases. The interface between the case sources and DONS is web-based. To report a case, a case reporter must visit the secure DONS web page, where he logs in and fills the online form of the disease that he wants to report.

DONS can share information with local institutions, such as health institutions, research institutions, universities, and government institutions. DONS can also share information with international health institutions, such as WHO, and other disease outbreak notification systems. An example of information that can be shared with international health organizations includes how to detect a potential outbreak of a certain disease. DONS can also share information about new outbreak diseases in the Kingdom with selected international health institutions. The level of information sharing with each institution is different and will be decided by both parties. The information shared is usually via import and the export of files. 
DONS has a list of experts to whom it notifies potential disease outbreaks. An expert is a physician, an epidemiologists or a medical professional who is specialized in one or more of the notifiable diseases. When DONS detects a potential disease outbreak, it notifies the appropriate experts by sending messages to their preferred way of notification (SMS, email or phone call). The expert can then login to DONS website and gets more information about the outbreak. He can also write his feedback into DONS. DONS uses expert feedbacks to improve its accuracy of detecting potential disease outbreaks and to adapt to new situations.

We propose that a generic DONS must consists of at least eight main modules. These modules are the Extraction, Transformation and Loading (ETL) module, the DONS database, the detection module, the notification module, the feedback module, the export and import module, the operation module, and the learning module. Figure 6 shows the block diagram of DONS.

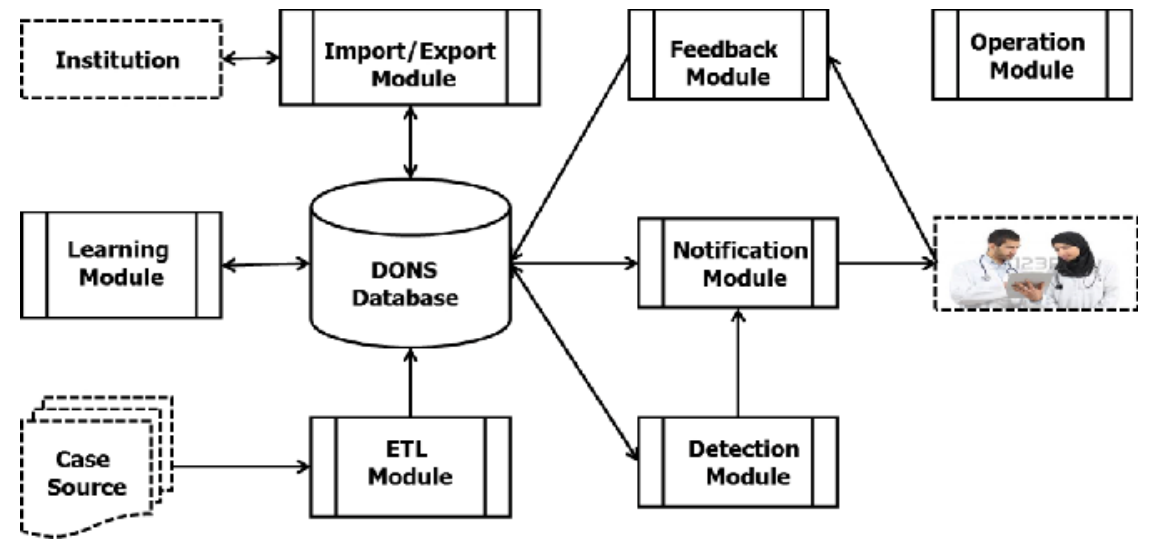

Figure 6: DONS Block Diagram

The ETL Module receives new cases form the case sources, transforms them and loads them to the DONS database. New cases are reported by the case sources in one of two ways. In the first way, the case reporter goes to the DONS login web page, logs in to the DONS and fills the online form associated with the disease. In the second way, an ETL client process runs regularly in the case sources machine, scans the source database, and sends new cases of notifiable diseases to the DONS system. The new case is then stored in the DONS database. If the new disease is not in the DONS database, its symptoms are inserted into the database and they are also sent to experts. Figure 7 shows the activity diagram of the ETL module.

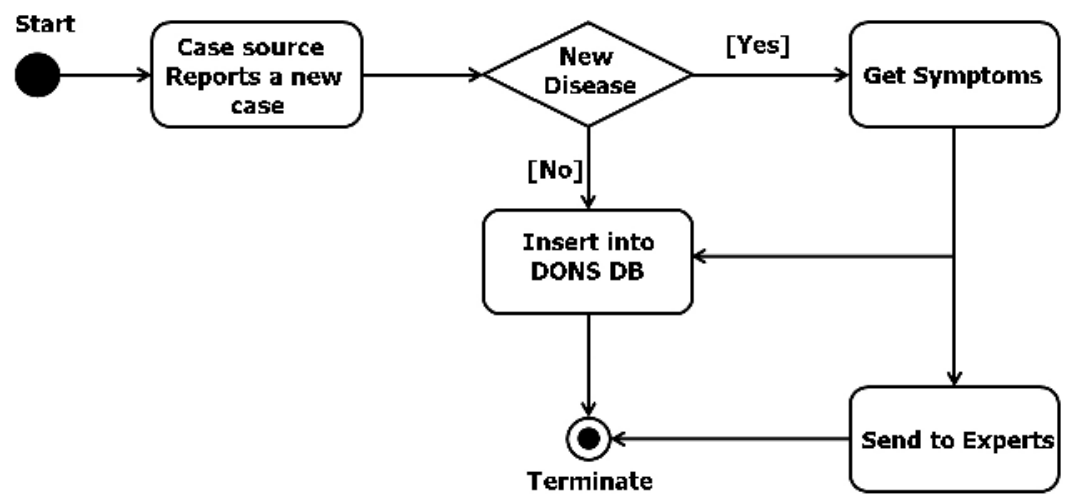

Figure 7: The ETL module activity diagram 
The DONS Database Module consists of many tables. Some of its main tables, we propose, are are: Disease, Symptom, Case, Patient, DetectionAlgorithm, DetectionAlgorithmParameter, Institution, Expert, HealthUnit, and Feedback. The Detection Module uses a number of statistical algorithms to detect a potential disease outbreak. Some of these algorithms are: SaTScan Poisson, SaTScan Space-Time permutation [22]-[24], and Farrington [25]. The detection module uses different algorithms to detect different disease outbreaks [26]-[29]. Also the actual parameters of each detection algorithm are different for different diseases. DONS keeps the relationship between a disease, a detection algorithm, and the corresponding actual parameter in its database which makes it dynamic. The detection module contains a daemon which regularly checks the Event table. The Event table contains the events that trigger a particular detection algorithm to run. The detection algorithm scans the DONS database for any potential outbreaks. If it detects no potential outbreaks it terminates; and if it detects a potential disease outbreak it send the information to the notification module, its updates the database, and it terminates. Figure 8 shows the activity diagram of the Detection Algorithm.

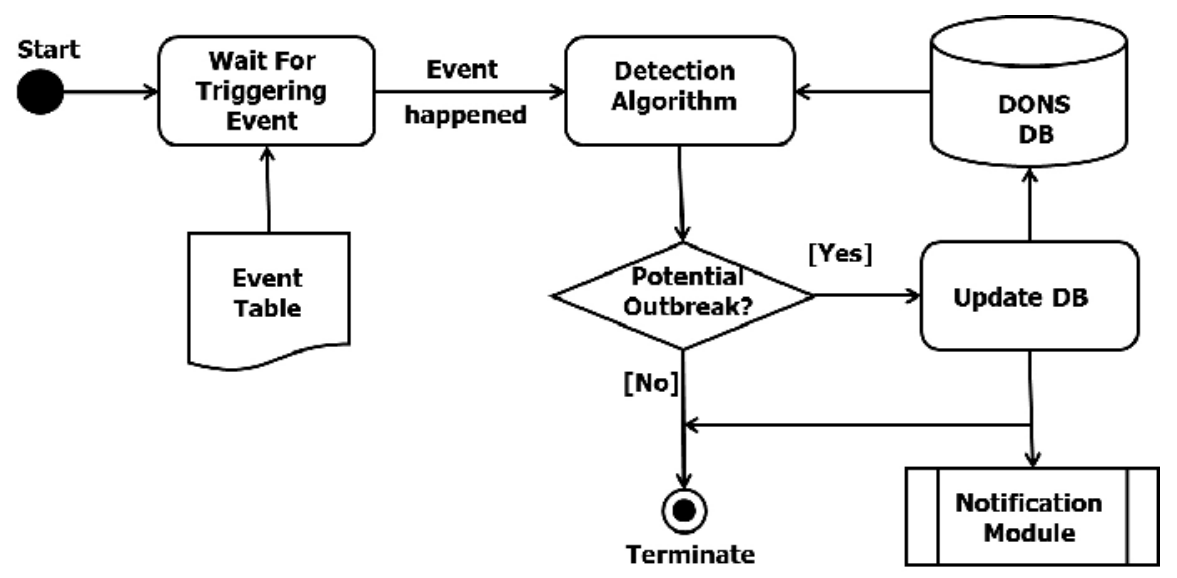

Figure 8: The Detection module activity diagram

When the detection module detects a potential disease outbreak it passes that information to the notification module. The notification module then reads the appropriate experts from the database and notifies them about the potential disease outbreak. The expert can then login to the DONS system and read detailed information about the diseases from the notification module.

After the Notification Module notifies an expert about a potential disease outbreak, the expert evaluates the accuracy of the notification and gives his feedback. The feedback is mainly given through an online questionnaire and is stored in the DONS database.

The Learning Module enables DONS to handle new diseases and to tune the detection algorithm actual parameters. It first builds a clustering model by learning the symptoms of the notifiable diseases. It then uses the model to predict the cluster of a new disease. From the cluster of the new disease it associates the new disease to a particular detection algorithm and actual parameters which can then be modified from the feedback of the experts.

The Import and Export Module is the interface between DONS and the institutions that share information with it. Typical examples of information that are shared by these institutions are information about new diseases, detection algorithms, and detection algorithm parameter values. This module consists of a query builder, query processor and information formatter. The query builder builds the queries that are sent to the institutions. The query processor answers queries received from the institutions. The formatter formats the information received from the institutions before they are stored in to the DONS database. The kind of information it shares with 
each institution is stored in the DONS database. Figure 9 (a) shows the Import moduleand Figure 9 (b) shows the Export module.

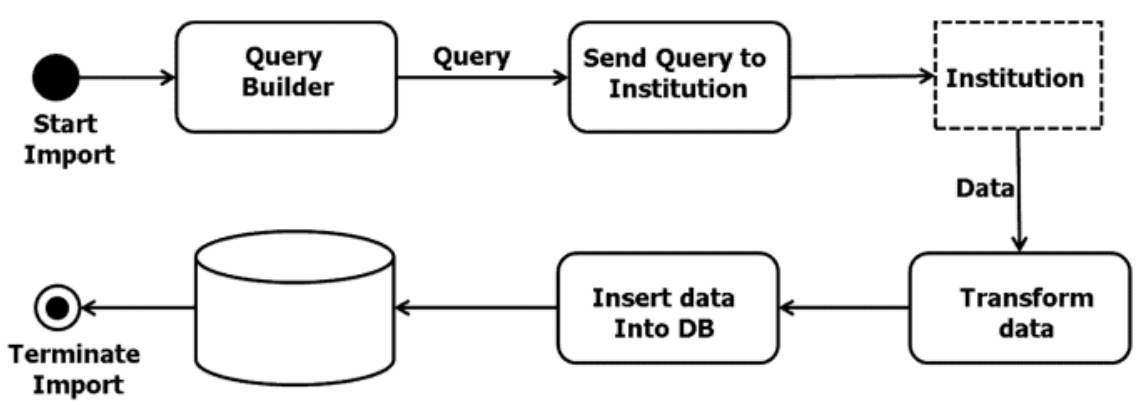

(a)

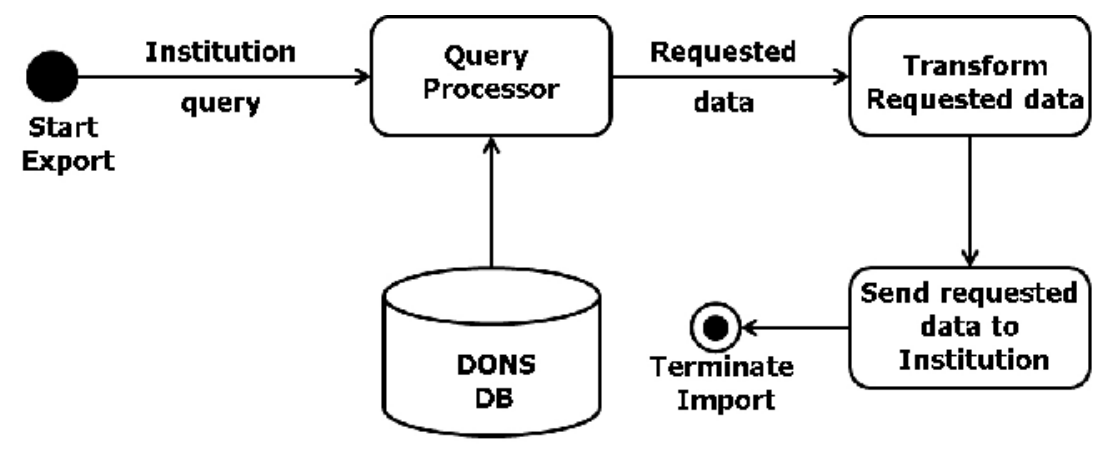

(b)

Figure 9: (a) The Import module (b) the Export module

The Operation Module contains the tools and the personnel that manage, develop, and maintain the DONS. They personnel include system analysts, developers, database administrators, network administrators, system administrators, disease outbreak experts, managers, operators and others.

\section{Conclusions}

We have presented a study of disease outbreak detection, monitoring and notification systems that play an important role in assessing threats to public health. The current systems world-wide use different taxonomies and classifications for the detection and prioritization of potential disease outbreaks. Based on our study and analysis of the current disease outbreak systems, we extracted features and functions of typical and generic disease outbreak systems. The paper proposes the generic model for disease outbreak systems that we believe would be ideal for such systems design, development and implementation. The entire effort was also directed towards standardizing the design process for typical disease outbreak systems.

\section{ACKNOWLEDGMENT}

The authors would like to acknowledge the support provided by the Deanship of Scientific Research at King Fahd University of Petroleum \& Minerals (KFUPM). This project is funded by King Abdulaziz City for Science and Technology (KACST) under the National Science, Technology, and Innovation Plan (project number 11-INF1657-04). 


\section{REFERENCES}

[1] "WHO | Influenza at the Human-Animal Interface (HAI)." [Online]. Available: http://www.who.int/influenza/human_animal_interface/en/. [Accessed: 11-Feb-2014].

[2] C.A. Bradley, H. Rolka, D. Walker, J. Loonsk, and others, "BioSense: implementation of a national early event detection and situational awareness system,” MMWR Morb Mortal Wkly Rep, vol. 54, no. Suppl, pp. 11-19, 2005.

[3] B.Cakici, K. Hebing, M. Grünewald, P. Saretok, and A. Hulth, "CASE: a framework for computer supported outbreak detection,” BMC Med. Inform. Decis. Mak., vol. 10, no. 1, p. 14, 2010.

[4] "National Notifiable Diseases Surveillance (NNDSS)." [Online]. Available: http://www.health.gov.au/internet/main/publishing.nsf/content/cda-surveil-nndss-nndssintro.htm.

[5] J.S. Brownstein, C. C. Freifeld, B. Y. Reis, and K. D. Mandl, "Surveillance Sans Frontieres: Internetbased emerging infectious disease intelligence and the HealthMap project," PLoS Med., vol. 5, no. 7, p. e151, 2008.

[6] E.N. Naumova, E. O'Neil, and I. MacNeill, "INFERNO: a system for early outbreak detection and signature forecasting,” MMWR Morb Mortal Wkly Rep, vol. 54, pp. 77-83, 2005.

[7] A.Zelicoff, J. Brillman, D. W. Forslund, J. E. George, S. Zink, S. Koenig, T. Staab, G. Simpson, E. Umland, and K. Bersell, "The Rapid Syndrome Validation Project (RSVP).," in Proceedings of the AMIA Symposium, 2001, p. 771.

[8] B.Y. Reis, C. Kirby, L. E. Hadden, K. Olson, A. J. McMurry, J. B. Daniel, and K. D. Mandl, “AEGIS: a robust and scalable real-time public health surveillance system," J. Am. Med. Informatics Assoc., vol. 14 , no. 5, pp. 581-588, 2007.

[9] J.M.Wilson, "Argus: a global detection and tracking system for biological events," Adv. Dis. Surveill., vol. 4, p. 21, 2007.

[10] D.Siegrist and J. Pavlin, "Bio-ALIRT biosurveillance detection algorithm evaluation,” MMWR Morb Mortal Wkly Rep, vol. 53, no. Suppl, pp. 152-158, 2004.

[11] V.M.S.Zaheer S. Winn J. Perry, "Implementation of the BioDefend? syndromic surveillance system: electronic format versus web-base data entry," Adv. Dis. Surveill., 2007.

[12] M. G. Baker and D. P. Fidler, "Global public health surveillance under new international health regulations.,” Emerg. Infect. Dis., vol. 12, no. 7, 2006.

[13] M.J. O’Connor, D. L. Buckeridge, M. Choy, M. Crubezy, Z. Pincus, and M. A. Musen, "BioSTORM: a system for automated surveillance of diverse data sources," in AMIA Annual Symposium Proceedings, 2003, vol. 2003, p. 1071.

[14] W.K.Yih, B. Caldwell, R. Harmon, K. Kleinman, R. Lazarus, A. Nelson, J. Nordin, B. Rehm, B. Richter, D. Ritzwoller, and others, "National bioterrorism syndromic surveillance demonstration program,” MMWR Morb Mortal Wkly Rep, vol. 53, no. 43, p. 9, 2004.

[15] C. C. Diamond, F. Mostashari, and C. Shirky, "Collecting and sharing data for population health: a new paradigm,” Health Aff., vol. 28, no. 2, pp. 454-466, 2009.

[16] M.L. Hutwagner, M. W. Thompson, G. M. Seeman, and T. Treadwell, "The bioterrorism preparedness and response early aberration reporting system (EARS)," J. Urban Heal., vol. 80, no. 1, pp. i89-i96, 2003.

[17] J.S.Lombardo, H. Burkom, and J. Pavlin, "ESSENCE II and the framework for evaluating syndromic surveillance systems,” MMWR Morb Mortal Wkly Rep, vol. 53, no. Suppl, pp. 159-165, 2004.

[18] P.Guglielmetti, D. Coulombier, G. Thinus, F. Van Loock, and S. Schreck, "The early warning and response system for communicable diseases in the EU: an overview from 1999 to 2005.," Euro Surveill. Bull. Eur. sur les Mal. Transm. Eur. Commun. Dis. Bull., vol. 11, no. 12, pp. 215-220, 2005.

[19] "The European Surveillance System (TESSy)." [Online]. Available: http://www.ecdc.europa.eu/en/activities/surveillance/TESSy/Pages/TESSy.aspx. [Accessed: 04-Mar2013].

[20] N.E.D.S.S.W. Group and others, "National Electronic Disease Surveillance System (NEDSS): a standards-based approach to connect public health and clinical medicine.," J. public Heal. Manag. Pract. JPHMP, vol. 7, no. 6, p. 43, 2001.

[21] P. Rolfhamre, A. Jansson, M. Arneborn, and K. Ekdahl, "SmiNet-2: Description of an internet-based surveillance system for communicable diseases in Sweden.," Euro Surveill. Bull. Eur. sur les Mal. Transm. Eur. Commun. Dis. Bull., vol. 11, no. 5, pp. 103-107, 2005.

[22] "SaTScan software for the spatial, temporal, and space-time scan statistics." [Online]. Available: http://www.satscan.org. 
[23] “SaTScan Users Guide Report.” [Online]. Available: http://www.satscan.org/techdoc.html.

[24] "SaTScan Version History Report." [Online]. Available: http://www.satscan.org/techdoc.html.

[25] C.P. Farrington, N. J. Andrews, A. D. Beale, and M. A. Catchpole, "A statistical algorithm for the early detection of outbreaks of infectious disease,” J. R. Stat. Soc. Ser. A (Statistics Soc., pp. 547563, 1996.

[26] A.M. Pelecanos, P. A. Ryan, and M. L. Gatton, "Outbreak detection algorithms for seasonal disease data: a case study using ross river virus disease,” BMC Med. Inform. Decis. Mak., vol. 10, no. 1, p. 74, 2010.

[27] A.H. A.M. Kling M. Grünewald, "CASE User Manual (2012), Algorithms, parameter settings and Evaluation Module.” 2012.

[28] M.Kulldorff, R. Heffernan, J. Hartman, R. Assunçao, and F. Mostashari, "A space--time permutation scan statistic for disease outbreak detection,” PLoS Med., vol. 2, no. 3, p. e59, 2005.

[29] A.M. Kling, K. Hebing, M. Grünewald, and A. Hulth, "Two Years of Computer Supported Outbreak Detection in Sweden: the User's Perspective.," J. Heal.Med. Informatics, vol. 3, no. 1, 2012.

[30] P.Jen-Hwa Hu, D. Zeng, H. Chen, C. Larson, W. Chang, C. Tseng, and J. Ma, "System for infectious disease information sharing and analysis: design and evaluation," Inf. Technol. Biomed. IEEE Trans., vol. 11, no. 4, pp. 483-492, 2007.

\section{Authors}

Farag Azzedin is an associate professor at the Department of Information and Computer Science, King Fahd University of Petroleum and Minerals (KFUPM), Dhahran, Saudi Arabia. He received his BSc degree in Computer Science from the University of Victoria, Canada. He received an MSc degree as well as a $\mathrm{PhD}$ degree in Computer Science from the Computer Science Department at the University of Manitoba, Canada.

Jaweed Yazdani is a faculty member at the Department of Information and Computer Science at King Fahd University of Petroleum and Minerals (KFUPM), Dhahran, Saudi Arabia and a manager of Administrative Information Systems (ADIS) at KFUPM. He received his MS degree and a BS degree in Computer Science from King Fahd University of Petroleum \& Minerals.

Salahadin Adam is an assistant professor at the Department of Information and Computer Science, King Fahd University of Petroleum and Minerals (KFUPM). He received his BS and MS degrees in Computer Science from KFUPM. He received a $\mathrm{PhD}$ degree in Computer Science from the Computer Science Department at the Monash University, Melbourne, Australia.

Mustafa Ghaleb earned his BS in computer science at King Khalid University (KKU), Abha, KSA in 2007. At the moment, he is pursuing his MS degree in Information \& Computer Sciences at King Fahd University of Petroleum \& Minerals (KFUPM).
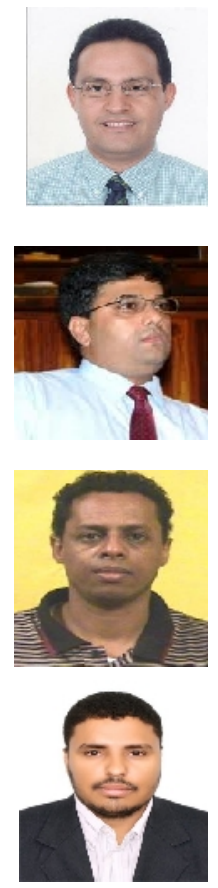